\section{Clinical importance of long-term antidepressant treatment}

ROBERT M. A. HIRSCHFELD
Concepts of depression have changed markedly over the past century. In the early part of the 20th century, Kraepelin described depression as a long-term affliction, characterised by recurrences and chronicity. In the 1960 s and 1970 s came the psychopharmacological revolution. Newly developed medications for depression - monoamine oxidase inhibitors (MAOIs) and tricyclic antidepressants (TCAs) - caused dramatic improvement within weeks. These developments led to a reformulation of depression as an illness that could be 'cured' quickly, like a bacterial infection. The development of short-term, focused psychotherapies such as cognitive-behavioural and interpersonal therapy paralleled the psychopharmacological advances, and also fostered this view of depression as a short-term illness.

Research findings emerging in the 1980 s challenged this view. For example, the National Institute of Mental Health Collaborative Program of the Psychobiology of Depression involved a multi-year follow-up of over 400 patients. After 15 years, only one in eight of these patients had recovered from their original episode and stayed well (Keller et al, 1992). Over $80 \%$ had suffered at least one recurrence, and $6 \%$ had remained chronically depressed throughout the entire 15-year period.
These and other findings, as well as experience with antidepressant pharmacotherapy, have led physicians to return to the Kraepelinean notion of depression as a long-term, recurrent and often chronic illness. Treatment for the disorder has both short-term and long-term aspects: shortterm treatment includes acute and continuation phases, while long-term treatment consists of the maintenance phase (Kupfer, 1991).

The acute phase involves stabilisation of the acute symptoms and generally lasts up to 3 months (Fig. 1). However, in complicated cases, acute treatment may take considerably longer. The continuation phase begins with stabilisation and ends at the point at which the depression would have ended had there been no successful treatment (often thought to be an additional 6-12 months beyond acute symptom resolution). If depressive symptoms return during the continuation period, it is considered to be a relapse into the original episode of illness. Thus, treatment for a single episode can take over a year, but in most cases will last 6-12 months. The maintenance phase involves prevention of new episodes (recurrences) and can extend for years.

\section{ACUTE TREATMENT}

The efficacy of pharmacotherapy for the acute phase of the treatment of depression is well established. Janicak et al (1997) summarised nearly 80 studies of TCAs and 16 studies of MAOIs in the acute treatment of major depression. He concluded that the statistical likelihood of chance being responsible for the active drug-placebo difference was less than $10^{-40}$ for TCAs and less than $10^{-11}$ for MAOIs. In his meta-analysis, nearly two-thirds of patients

will have a recurrence rate of between

$10 \%$ and $30 \%$.

Conclusions Risk of relapse and recurrence of depression can be significantly reduced if adequate continuation and maintenance therapy durations are achieved.

Declaration of interest R.M.A.H. received an honorarium and travel expenses from Eli Lilly \& Co.

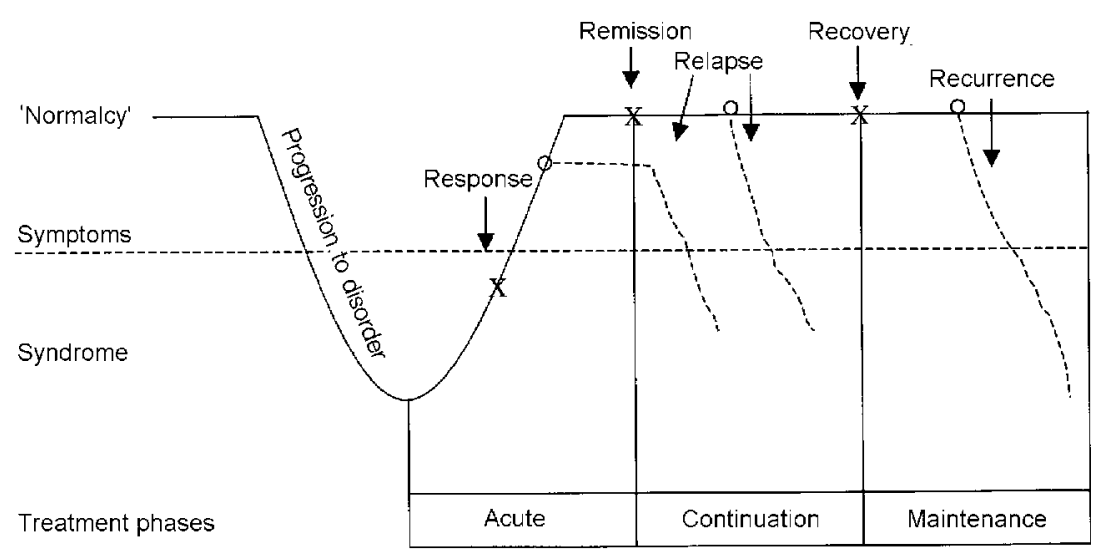

Fig. I Response, remission, recovery, relapse and recurrence of depression. From Kupfer (1991). 
responded to active drug, whereas about one-third responded to placebo. These analyses reveal a substantial drug effect, but many patients (one-third) continue to suffer from symptoms of depression even after vigorous treatment. Thus, the effect size is less than many would hope for.

\section{CONTINUATION TREATMENT}

The second phase of short-term antidepressant treatment is the continuation phase. The purpose of continuation treatment is to prevent relapse, the re-emergence of symptoms, following premature withdrawal of medication after acute stabilisation has been achieved. The number of studies on continuation therapy is small compared with those on acute therapy. The key question in these studies is whether continued treatment on medication is necessary after acute stabilisation of symptoms.

Six continuation studies of TCAs, primarily amitriptyline, were identified (Table 1). Overall, less than one-fifth of those on active drug therapy relapsed compared with over half of those on placebo.

Several similarly designed studies of selective serotonin reuptake inhibitors (SSRIs) and other newer agents have also been conducted. For example, in an international, multi-centre study, 467 patients with major depressive disorder were enrolled in an open-label trial of sertraline for 8 weeks (Doogan \& Caillard, 1992). Of the 300 responders, 185 agreed to be randomised either to stay on sertraline or to be blindly switched to placebo. After approximately 10 months of follow-up, nearly $13 \%$ of patients taking active medication relapsed compared with $46 \%$ on placebo $(P<0.001)$ (Doogan \& Caillard, 1992). Most of the relapses in this study occurred within the first 6 months of continuation treatment (Fig. 2).

Additional continuation studies involving paroxetine, nefazodone, citalopram, reboxetine, amineptine and fluoxetine, with nearly identical protocol designs, gave very similar results (Montgomery \& Dunbar, 1993; Montgomery et al, 1993; Robert \& Montgomery, 1995; Ferreri et al, 1997; Reimherr et al, 1998; Feiger et al, 1999; Versiani et al, 1999). Approximately onethird to one-half of patients who did not continue active treatment after stabilisation (i.e. were switched to placebo) relapsed,

Table I Continuation studies in depression

\begin{tabular}{llll}
\hline & Drug & Relapse rate \\
\cline { 2 - 3 } & & Active drug (\%) Placebo (\%) \\
\hline Studies of tricyclic antidepressants & & & \\
Seager \& Bird (1962) & Imipramine & 17 & 69 \\
Mindham et al (1973) & Amitriptyline or imipramine & 22 & 50 \\
Prien et al (1973) & Imipramine & 37 & 67 \\
Klerman et al (1974) & Amitriptyline & 12 & 29 \\
Coppen et al (1978) & Amitriptyline & 0 & 31 \\
Stein et al (1980) & Amitriptyline & 28 & 69 \\
Studies of newer agents & & & 46 \\
Doogan \& Caillard (1992) & Sertraline & 13 & 43 \\
Montgomery \& Dunbar (1993) & Paroxetine & 16 & 33 \\
Feiger et al (1999) & Nefazodone & 17 & 24 \\
Robert \& Montgomery (1995) & Citalopram & 14 & 31 \\
Montgomery \& Dunbar (1993) & Citalopram & 11 & 56 \\
Versiani et al (1999) & Reboxetine & 22 & 19 \\
Ferreri et al (1997) & Amineptine & 26 & 49 \\
Reimherr et al (1998) & Fluoxetine & & \\
\hline & & & \\
\hline
\end{tabular}

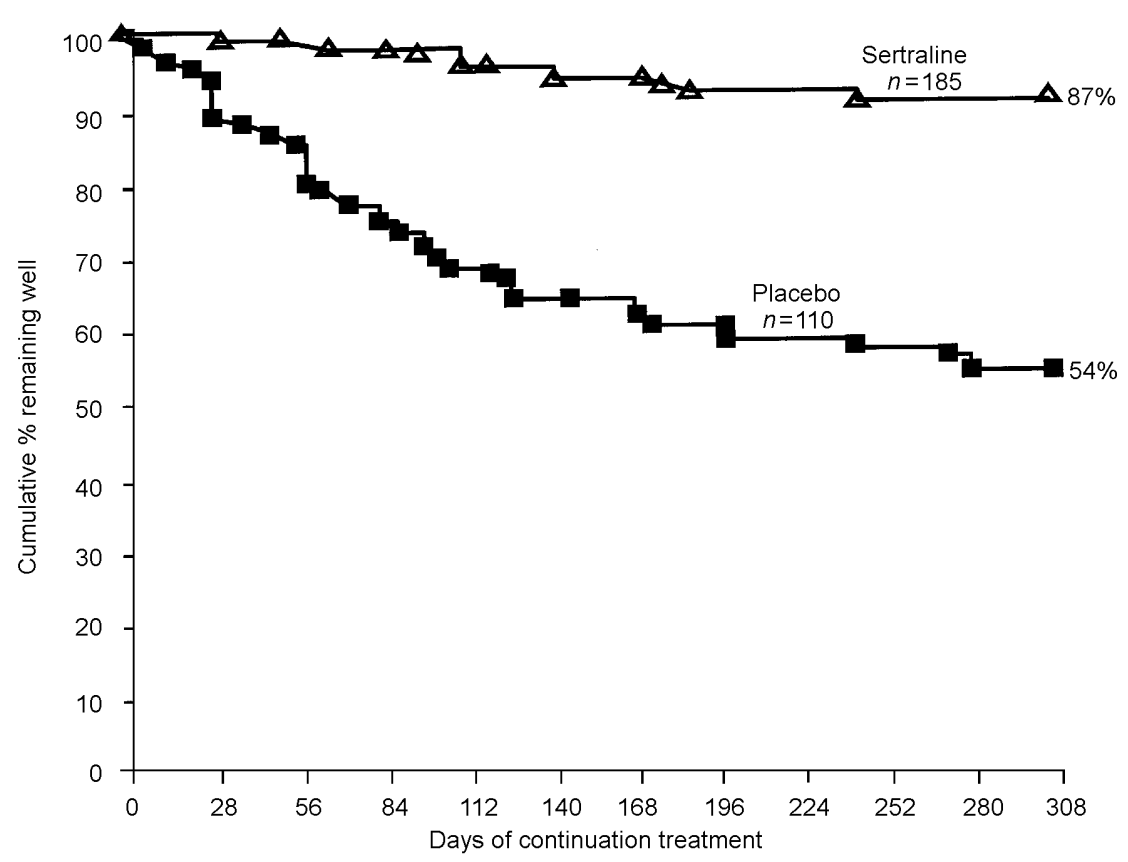

Fig. 2 Patients not relapsing during continuation study of sertraline. From Doogan \& Caillard (1992).

whereas about $15 \%$ relapsed if they continued on active medication (Table 1).

The continuation study conducted by Reimherr et al was designed to assess not only rates of relapse, but also the question of how long continuation therapy should last. Patients with major depression were treated in an open-label trial with $20 \mathrm{mg}$ per day of fluoxetine for 12 weeks (Reimherr et al, 1998). Patients who had sustained remission during this period were randomised either to continue on fluoxetine or to be blindly switched to placebo. Groups of patients in the fluoxetine arm were then randomised to placebo after a further 14 or 18 weeks (for a total of 26 or 50 weeks of treatment), or were maintained on fluoxetine for the entire 50 weeks of the 

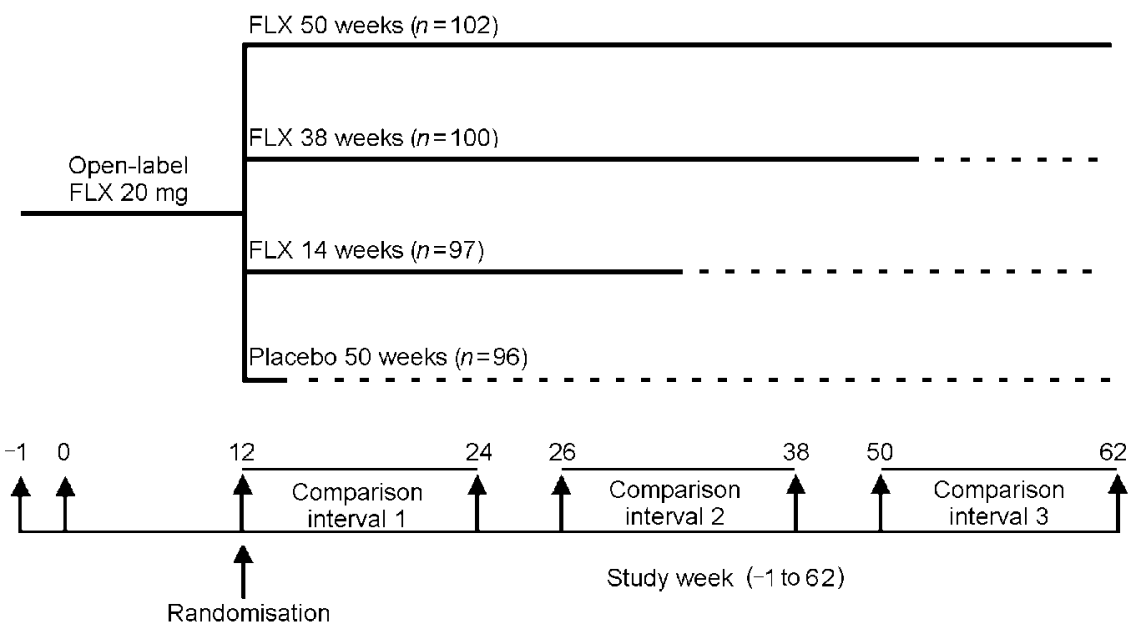

Fig. 3 Fluoxetine (FLX) continuation study design. From Reimherr et al (1998). continuation period (for a total of 62 weeks of treatment) (Fig. 3).

The results for the patients who were randomised at week 12 to placebo compared

(a)

(b)

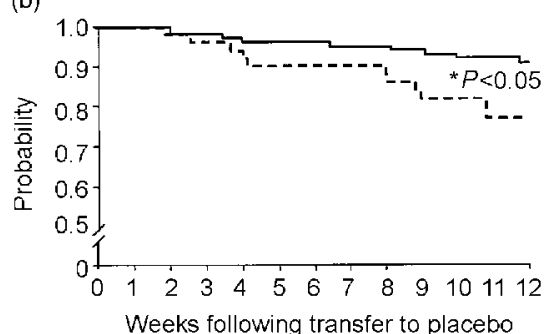

(c)

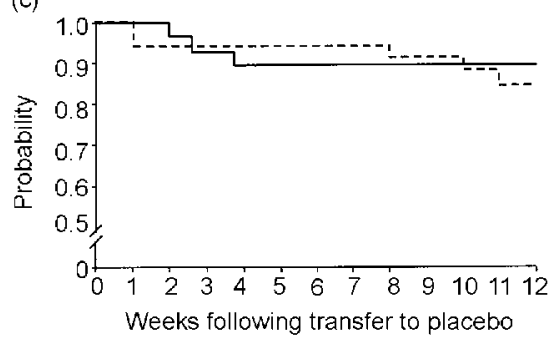

Fig. 4 Cumulative probability of remaining well during continuation treatment with fluoxetine (solid lines) or placebo (dashed lines). (a) Comparison interval I (weeks 12-24); (b) interval 2 (weeks 26-38); (1998).

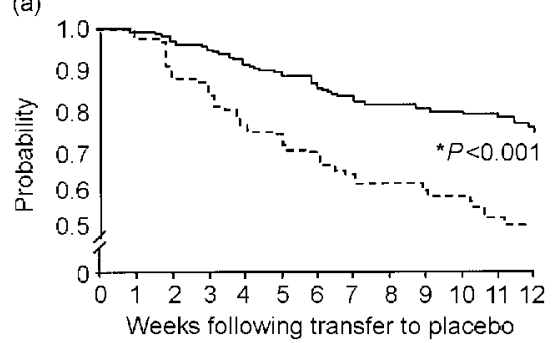
(c) interval 3 (weeks 50-62). From Reimherr et al following remission, but in most patients need not be given beyond 9 months following remission.

In summary, results of continuation studies of both older and newer classes of antidepressant consistently demonstrate that approximately one-third to half of all patients will relapse if medication is not sustained throughout the continuation period. Only $10-15 \%$ will relapse if medication is continued. The results from the study by Reimherr et al indicate that continuation therapy should last at least 3-9 months following remission.

\section{MAINTENANCE TREATMENT}

The objective of maintenance therapy, the long-term aspect of antidepressant treatment, is to prevent the occurrence of a new episode of depression after full recovery from a previous episode. Maintenance therapy should be strongly considered for all patients at risk of recurrence. Such patients are those with a history of three or more prior episodes of major depression, preexisting dysthymia, severe episodes, seasonal patterns, a familial history of affective disorder, a poor response to continuation therapy, and comorbid anxiety (or similar disorders) or substance misuse problems (Hirschfeld \& Schatzberg, 1994).

A number of maintenance therapy studies have been performed using TCAs and one has been performed using an MAOI (Table 2). Although the recurrence rates for active drug versus placebo differ in these studies, the data consistently demonstrate a significantly higher rate of recurrence in results suggest that continuation therapy should be given for at least 3 months

Table 2 Maintenance studies in depression
Drug Recurrence rate

Active drug (\%) Placebo (\%)
Studies of TCA/MAOI
Kane et al (1982)
Prien et al (1984)
Frank et al (1990)
Robinson et al (1991)
Kocsis et al (1996)
Studies of newer agents
Montgomery et al (1988)
Terra \& Montgomery (1998)
Keller et al (1998)

Old Age Depression Interest Group (1993)
Imipramine

Imipramine

Imipramine

Phenelzine

Dothiepin

Desipramine

Fluoxetine

Fluvoxamine

Sertraline

$\begin{array}{lr}66 & 100 \\ 33 & 65 \\ 20 & 90 \\ 29 & 81 \\ 40 & 60 \\ 11 & 52\end{array}$

MAOI, monoamine oxidase inhibitor; TCA, tricyclic antidepressant. 


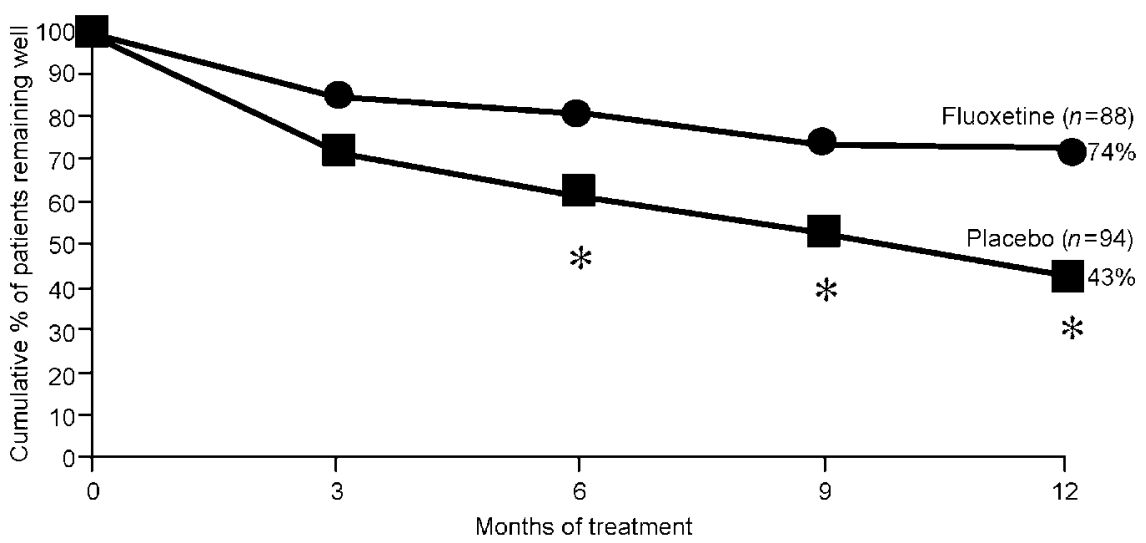

Fig. 5 Patients without recurrence of depression during I-year maintenance study; $* P<0.0$ I. From Montgomery et al (1988)

patients given placebo compared with those who continue on active drug therapy. While these older classes of antidepressants have proven clinical efficacy, their use in the real world is hampered by concerns about side-effects (including anticholinergic, cardiovascular and histaminic effects), which can lead to non-compliance, as well as the risk of fatal overdose in patients who stockpile medication.

Maintenance studies involving the SSRIs fluoxetine, fluvoxamine and sertraline have also been performed. In one study, 456 patients with DSM-III (American Psychiatric Association, 1980) recurrent major depression were treated with open-label fluoxetine for 6 weeks (Montgomery et al, 1988). Those who responded were continued on fluoxetine therapy for an additional 18 weeks. Those who completed this 24 weeks of treatment were randomised to continue with fluoxetine $(n=88)$ or to switch blindly to placebo $(n=94)$. Recurrence of depression was defined by a score above 18 on the Hamilton Rating Scale for Depression (Hamilton, 1967). A recurrence rate of $26 \%$ occurred in the fluoxetine group during the 1-year follow-up compared with $57 \%$ in the placebo group $(P<0.001)$ (Fig. 5).

A similarly designed study using fluvoxamine gave results consistent with those observed in the fluoxetine study. A mean daily dose of $100 \mathrm{mg}$ of fluvoxamine was shown to be effective in preventing recurrence of DSM-III-R (American Psychiatric Association, 1987) major depressive disorder. Recurrence was defined as a reappearance of depressive symptoms in the opinion of the investigator. The fluvoxamine group had a recurrence rate of $13 \%$, whereas the placebo group had a recurrence rate of
35\% $(P<0.001)$ (Terra \& Montgomery, 1998).

The studies described above and summarised in Table 2 suggest that, among patients at risk, depression will recur in approximately $60 \%$ within 1 year if untreated. If patients continue to receive treatment with newer antidepressants, the recurrence rate drops to between $10 \%$ and $30 \%$ (Table 2 ). This clearly supports the efficacy and advisability of maintenance treatment if patients are among those at risk.

\section{CONCLUSION}

Depression is a recurrent and often a lifelong illness, which requires long-term treatment. The notions prevalent in the 1960s and 1970s that depression could be treated successfully within a period of weeks have been modified in the light of substantial evidence to the contrary. All patients with major depression who have successfully responded to an antidepressant drug should be continued on medication for a period of 3-6 months beyond acute symptom resolution. If not, up to half of them will relapse back into their original episode. Patients at risk of recurrence should be considered for maintenance therapy. Such patients will almost certainly experience a recurrence of depression within several years without continued treatment.

\section{REFERENCES}

American Psychiatric Association (1980) Diagnostic and Statistical Manual of Mental Disorders (3rd edn) (DSM-III). Washington, DC: APA.
- (1987) Diagnostic and Statistical Manual of Mental Disorders (3rd edn, revised) (DSM-III-R). Washington, DC: APA

Coppen, A., Ghose, K., Montgomery, S., et al (1978) Continuation therapy with amitriptyline in depression. British Journal of Psychiatry, 133, 28-33.

Doogan, D. P. \& Caillard, V. (1992) Sertraline in the prevention of depression. British Journal of Psychiatry, 160, 217-222.

Feiger, A. D., Bielski, R. J., Bremner, J., et al (1999) Double-blind, placebo-substitution study of nefazodone in the prevention of relapse during continuation treatment of outpatients with major depression. International Clinical Psychopharmacology, 4, 19-28.

Ferreri, M., Colonna, L. \& Leger, J. M. (1997) Efficacy of amineptine in the prevention of relapse in unipolar depression. International Clinical Psychopharmacology, 12 (suppl. 3), S39-S45.

Frank, E., Kupfer, D. J., Perel, J. M., et al (1990) Three-year outcomes for maintenance therapies in recurrent depression. Archives of General Psychiatry, 47, 1093-1099.

Hamilton, M. (1967) Development of a rating scale for primary depressive illness. British Journal of Social and Clinical Psychology, 6, 278-296.

Hirschfeld, R. M. A. \& Schatzberg, A. F. (1994)

Long-term management of depression. American Journal of Medicine, 97 (suppl. 6A), 33S-38S.

Janicak, P. G., Davis, J. M., Preskorn, S. H., et al (1997) Treatment with antidepressants. In Principles and Practice of Psychopharmacology (2nd edn), pp. 243-356. Baltimore, MD: Williams \& Wilkins.

Kane, J. M., Quitkin, F. M., Rifkin, A., et al (1982) Lithium carbonate and imipramine in the prophylaxis of unipolar and bipolar II illness: a prospective, placebocontrolled comparison. Archives of General Psychiatry, 39, 1065-1069.

Keller, M. B., Lavori, P. W., Mueller, T. J., et al (1992) Time to recovery, chronicity, and levels of psychopathology in major depression: a 5 -year prospective follow-up of 431 subjects. Archives of General Psychiatry, 49, 809-816.

— , Kocsis, J. H., Thase, M. E., et al (1998)

Maintenance phase efficacy of sertraline for chronic depression: a randomized controlled trial. Journal of the American Medical Association, 280, 1665-1672.

Klerman, G. L., Dimascio, A., Weissman, M., et al (1974) Treatment of depression by drugs and psychotherapy. American Journal of Psychiatry, I3I, |86-19|.

Kocsis, J. H., Friedman, R. A., Markowitz, J. C., et al (1996) Maintenance therapy for chronic depression. A controlled clinical trial of desipramine. Archives of General Psychiatry, 53, 769-774.

Kupfer, D. J. (1991) Long-term treatment of depression Journal of Clinical Psychiatry, 52 (suppl. 5), 28-34.

Mindham, R. H., Howland, C. \& Shepherd, M. (1973) An evaluation of continuation therapy with tricyclic antidepressants in depressive illness. Psychological Medicine, 3, 5- 17.

Montgomery, S. A. \& Dunbar, G. (1993) Paroxetine is better than placebo in relapse prevention and the prophylaxis of recurrent depression. International Clinical Psychopharmacology, 8, 189-195.

_ , Dufour, H., Brion, S., et al (1988) The prophylactic efficacy of fluoxetine in unipolar 
depression. British Journal of Psychiatry, 153 (suppl. 3), 69-76.

_, Rasmussen, J. G. C. \& Tanghoj, P. (1993) A 24 week study of $20 \mathrm{mg}$ citalopram, $40 \mathrm{mg}$ citalopram, and placebo in the prevention of relapse of major depression. International Clinical Psychopharmacology, 8, $181-188$.

Old Age Depression Interest Group (1993) How lon should the elderly take antidepressants? A double-blind placebo-controlled study of continuation/prophylaxis therapy with dothiepin. British Journal of Psychiatry,

162, 175-182.

Prien, R. F., Klett, C. J. \& Caffey, E. M. (1973) Lithium carbonate and imipramine in prevention of affective episodes. A comparison in recurrent affective illness. Archives of General Psychiatry, 29 420-425.

\section{_, Kupfer, D. J., Mansky, P. A., et al (1984)}

Drug therapy in the prevention of recurrences in unipolar and bipolar affective disorders. Report of the NIMH Collaborative Study Group comparing lithium carbonate, imipramine, and a lithium carbonateimipramine combination. Archives of General Psychiatry, 44, 1096-1104.

ROBERT M. A. HIRSCHFELD, MD, Department of Psychiatry and Behavioral Sciences, University of Texas Medical Branch at Galveston, I.302 Rebecca Sealy, 30I University Blvd, Galveston, TX 77555-0188, USA. Tel: + I 409747 979|; fax: + I 409747 8300; e-mail: rohirsch@utmb.edu

Reimherr, F. W., Amsterdam, J. D., Quitkin, F. M., et al (1998) Optimal length of continuation therapy in depression: a prospective assessment during long-term fluoxetine treatment. American Journal of Psychiatry, 155 1247-1253.

Robert, P. \& Montgomery, S. A. (1995) Citalopram in doses of 20-60 mg is effective in depression relapse prevention: a placebo-controlled 6 month study. International Clinical Psychopharmacology, 10 (suppl. I), 29-35.

Robinson, D. S., Lerfald, S. C., Bennett, B., et al (1991) Continuation and maintenance treatment of major depression with the monomaine oxidase inhibitor phenelzine: a double-blind placebo-controlled discontinuation study. Psychopharmacology Bulletin, 27, $31-39$
Seager, C. P. \& Bird, R. L. (1962) lmipramine with electrical treatment in depression - a controlled trial. Journal of Mental Science, 108, 704-707.

Stein, M. K., Rickels, K. \& Weise, C. C. (1980) Maintenance therapy with amitriptyline: a controlled trial. American Journal of Psychiatry, 37, 370-37।.

Terra, J. L. \& Montgomery, S. A. (1998) Fluvoxamine prevents recurrence of depression: results of a longterm, double-blind, placebo-controlled study. International Clinical Psychopharmacology, 13, 55-62.

Versiani, M., Mehilane, L., Gaszner, P., et al (1999) Reboxetine, a unique selective NRI, prevents relapse and recurrence in long-term treatment of major depressive disorder. Journal of Clinical Psychiatry, 60 , 400-406. 